\title{
Algunas reflexiones sobre la clasificación de los organismos vivos
}

\author{
Some reflections on the \\ classification of living \\ organisms
}

\author{
Rita Daniela Fernández Medina \\ Pós-doutora na Escola Nacional de Saúde Pública/ \\ Fundação Oswaldo Cruz. \\ Rua Leopoldo Bulhões, 1480 \\ 21041-210 - Rio de Janeiro - RJ - Brasil \\ daniela@fiocruz.br
}

Recebido para publicação em fevereiro de 2010.

Aprovado para publicação em abril de 2012.
FERNÁNDEZ MEDINA, Rita Daniela. Algunas reflexiones sobre la clasificación de los organismos vivos. História, Ciências, Saúde - Manguinhos, Rio de Janeiro, v.19, n.3, jul.-set. 2012, p.883-898.

\section{Resumen}

Clasificar es una manera de organizar la información que puede ser definida como una actividad donde diferentes objetos, conceptos o seres son asignados a categorías según algún criterio. Los criterios de clasificación de los organismos vivos han mudado a lo largo del tiempo. En el presente trabajo, a partir de un recorrido histórico se presentan las diferentes formas que han existido de clasificar a los organismos vivos. Se presentan también algunas discusiones existentes en relación a la forma en que se agrupan los organismos hoy en día, así como también los supuestos sobre los cuales se realiza dicha clasificación, como la noción de ancestro común, de jerarquía y divergencia, las nociones de categoría natural y de clasificaciones naturales dentro de las ciencias biológicas.

Palabras clave: organismos vivos; clasificación; filogenia; especie.

\section{Abstract}

Classifying is a way of organizing information, which can be defined as an activity where different objects, concepts or beings are assigned to categories according to a given criterion. The criteria for classification of living organisms have changed over the course of time. In this paper, based on a historical survey, the different ways that have existed for classifying living organisms are presented. Some current discussions regarding how organisms are grouped today are also presented, as well as the premises upon which such classifications are made, such as the notion of common ancestry, hierarchy and divergence, the notions of natural category and natural classifications within the biological sciences.

Keywords: living organisms; classification; phylogeny; species. 
The most important aspect of the history of systematics is that it is, like the history of evolutionary biology a history of concepts rather than facts.

(Ernst Mayr, 1982, p.144)

The time will come, I believe, though I shall not live to see it, when we shall have very fairly true genealogical trees of each great kingdom of nature.

(Charles Darwin, 1859, p.456)

La propuesta de este trabajo es intentar delinear algunas de las discusiones que existen en torno al sistema de clasificación de los organismos vivos que es considerada más apropiada hoy en día (Figura 1). Tres cuestiones básicas para ser pensadas surgen a partir de esta figura: cuáles son las herramientas que han posibilitado la construcción de este árbol, cuál es el mundo que representa y cuáles son los presupuestos sobre los cuales se basa esta clasificación.

Algunos de los puntos a pensar a partir de esta figura son los siguientes:

(a) La noción de ancestro u origen común;

(b) La noción de jerarquía y de divergencia;

(c) Las definiciones de especie y concepciones filosóficas de especie. La noción de categoría natural y clasificaciones naturales;

(d)El paradigma de la evolución y la biología molecular como herramienta necesaria y suficiente para responder a cualquier tipo de pregunta en biología.

\section{Algunas definiciones}

Como punto de partida comenzaré por definir los términos que van a manejarse en este trabajo. "Clasificar es la actividad mediante la cual objetos, conceptos y relaciones son asignadas a categorías; clasificar se refiere a los mecanismos culturales y cognitivos mediante los cuales esto es obtenido; y las clasificaciones resultantes son las representaciones lingüísticas, mentales y culturales que resultan de ello" (Ellen, 2010, p.129). Existen varias formas de ver similitudes y diferencias en cualquier conjunto de cosas. Pero cuando se habla de clasificaciones en ciencias procuramos sistemas que den información sobre las relaciones existentes entre las diferentes entidades a ser clasificadas. Como veremos más adelante, el sistema de clasificación de lo vivo utilizado hoy en día se basa en las relaciones genealógicas o filogenéticas entres los organismos y las clasificaciones resultantes son consideradas 'clasificaciones naturales'.

La ciencia que se encarga del estudio de las relaciones entre organismos y de las clasificaciones de los mismos es la sistemática. Ésta incluye varias disciplinas, entre las que se encuentra la taxonomía (del griego taxis = arreglo, poner orden, y nomos = ley) que es considerada el método sistemático de clasificar todo lo vivo (anteriormente solo animales 
y plantas, hoy en día también organismos como bacterias, hongos, etc.). En realidad, taxonomía y sistemática suelen utilizarse indistintamente como sinónimos.

Este trabajo, por tanto, trata sobre taxonomías. Comencemos por una breve cronología de las mismas a lo largo del tiempo.

\section{Las clasificaciones de lo'vivo' en la historia. El esencialismo en las clasificaciones}

El filósofo griego Aristóteles (384-322 a.C.) es considerado por muchos autores como el 'padre de las clasificaciones'. A partir del reconocimiento de la necesidad de agrupar y nombrar a plantas y animales para facilitar su estudio, dividió al mundo natural en dos grandes reinos: el reino animal y el vegetal. Inició su estudio y ordenación de las diversas formas de vida animal junto a su discípulo Teofrasto (371-287 a.C.), quien clasificó a los vegetales en árboles, arbustos y hierbas. Por su parte, Aristóteles clasificó a los animales en aquellos que tenían sangre y aquellos desprovistos, entre otras características. Dedujo que la naturaleza progresa desde lo más simple a lo más complejo, de lo inanimado a lo animado y dentro de lo animado, mediante pasos ascendentes desde las plantas a los animales. Aristóteles introdujo por primera vez el concepto de especie y concibió un mundo de especies estáticas, generadas en aproximación a una forma 'ideal'. Esto es, cada especie tendría una forma natural, un 'tipo' verdadero y la variación individual dentro de cada especie representaría desviaciones accidentales del tipo verdadero causadas por influencias externas. En la ausencia de influencias externas que causan la desviación, todos los individuos de una especie serían por siempre lo mismo, sin variación, ya que el tipo verdadero de la especie, permanece fijo en el tiempo

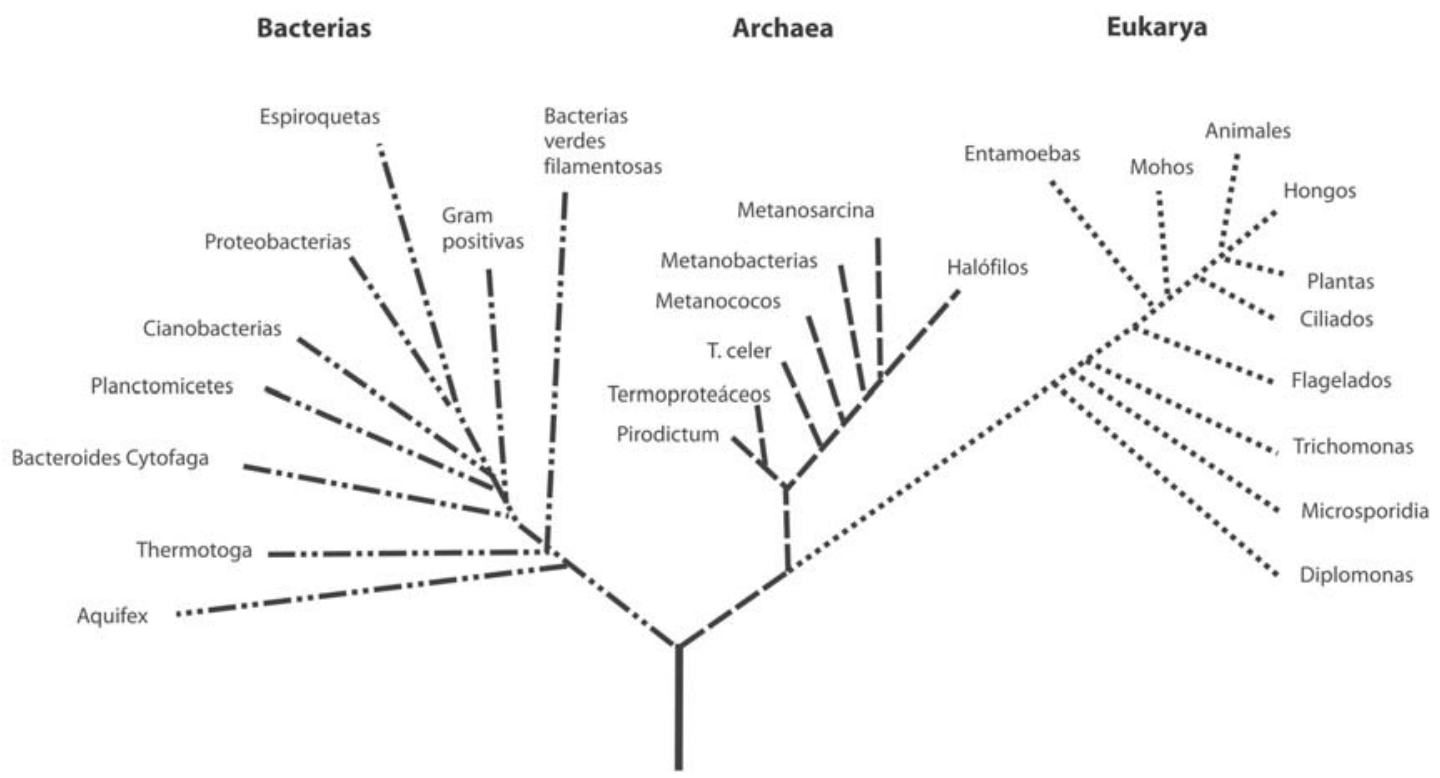

Figura 1: Sistema de clasificación universal basado en los tres dominios: bacteria, archae y eukarya. Obsérvese los reinos protista, animal, vegetal y hongos dentro del dominio eukarya (baseado em Woese, Kandler, Wheelis, 1990, p.4578) 
(O'Hara, 1997, p.324). Esta forma de pensamiento, conocida como esencialismo, dominó el mundo por varios siglos. En Physics, Aristóteles escribió: "Las cosas naturales son aquellas que se mueven constantemente hacia un objetivo determinado, en virtud de un principio inherente en ellas mismas; y el desarrollo final que resulta de cualquiera de esos principios no es idéntico para dos especies cualquiera, pero tampoco es un resultado aleatorio; en cada una hay siempre una tendencia hacia un resultado idéntico si nada interfiere con el proceso"1, (según cita en Bock, 1978, p.43).

En este sentido, todos los miembros de una clase tendrían características esenciales que permitirían alcanzar el ideal 'natural' que los distinguiría como miembros de una especie. Ideal que podría no ser alcanzado debido a causas externas o a fuerzas que interfiriesen con dicha tendencia natural. Bajo el esencialismo aristotélico, la variabilidad es vista como una interferencia o como un movimiento fuera de la norma ya que los seres animados serían generados por aproximación a una forma ideal de la especie a la cual pertenecen.

Otro actor fundamental en la historia de las clasificaciones científicas es el científico y naturalista sueco Carl Lineo (1707-1778) quien, sin duda alguna, marca un importante paso en el trabajo sistemático de clasificación de los organismos. Es importante remarcar que el sistema de nomenclatura propuesto por Lineo continúa en uso hasta nuestros días. Este sistema se conoce como sistema binomial ya que cada especie es denominada por dos nombres en latín. El primero que denota el género al cual pertenece y el segundo, la especie. Este sistema se basa en una forma jerárquica de organización de los organismos. Por otra parte, Lineo agrupa a los organismos de acuerdo a sus afinidades. Las especies, consideradas entidades reales - veremos más adelante algunas controversias sobre el concepto de especie y sobre su estatus ontológico -, son agrupadas basándose en similitudes y afinidades morfológicas, en géneros, los cuales, a su vez, son agrupados en órdenes, éstos en clases y por último las clases en reinos. Por lo tanto, en esa época se reconocían solo cinco categorías taxonómicas o taxa ${ }^{2}$ (especie, género, orden, clase y reino) mientras que hoy nuevos taxa han sido incorporados a la clasificación. La especie es considerada la categoría taxonómica donde los individuos muestran el mayor grado de similitud. No existen en esta concepción ideas evolucionistas. Lineo era creacionista y consideraba a las especies como entidades fijas, que no cambian ni se extinguen. Así se estableció lo que en ese momento fue llamado de Sistema Natural que es la noción de la existencia de un orden en la diversidad biológica. Este es uno de los grandes conceptos en la historia de la ciencia.

La ruptura con el esencialismo en las ciencias biológicas comienza a darse en el siglo XVIII, a partir de la crítica de dos de sus fundamentos: la relación natural entre categorías y entidades y el carácter inmutable de las especies. La primera crítica llegaría de la mano de nominalistas, como el naturalista suizo Charles Bonnet (1720-1793), quienes consideraban que todos los agrupamientos son artefactos de la mente humana y sostenían que únicamente los individuos tendrían una existencia real. Bonnet, en 1745, representa a la Cadena de los Seres como una columna ascendente que va desde la materia inanimada (aire, tierra, metales, etc.), pasando por las plantas, los insectos, hasta llegar al hombre por encima de todos los organismos. Esta escala estática, representando la naturaleza como una secuencia lineal que se extendía de lo menos a lo más complejo, fue reinterpretada hacia fines del siglo XVIII como un proceso que ocurría en el tiempo (McLaughin, 2001, p.13). En la medida que la 
diversidad de lo vivo era mejor conocida, comenzó a percibirse que la Cadena de los Seres era una forma inadecuada de representación del Sistema Natural.

\section{Ruptura con el esencialismo}

En el siglo XIX, varios autores comienzan a concebir un mundo en donde las especies mudan. La teoría de evolución del naturalista y académico francés Lamarck (1744-1829) fue elaborada a comienzos del siglo XIX (1809). Lamarck apoyaba la teoría, conocida como transformismo, que concebía que diferentes linajes habrían sido generados espontáneamente y que los mayores cambios dentro de cada uno de ellos ocurrían como resultado de una fuerza interna que los guiaba hacia un mayor grado de complejidad. Existía la noción de progreso hacia formas más avanzadas. Para Lamarck, los seres humanos de hoy en día pertenecerían a un linaje muy antiguo debido a su alto grado de complejidad, ya los gusanos actuales tendrían un origen más cercano debido a su menor grado de complejidad y, por lo tanto, no compartían un origen común con los humanos. Dos leyes fundamentales de su teoría fueron la 'ley de uso y desuso' de estructuras que llevaría al desarrollo o disminución de diferentes partes del cuerpo según su uso y la de los 'caracteres adquiridos' por la cual la progenie podría heredar caracteres adquiridos por sus progenitores en su vida adulta.

El naturalista inglés Charles Darwin (1809-1882) es considerado el mentor de un mundo en continuo cambio y un origen común para todos los organismos (no en tanto, nociones evolucionistas también lo antecedieron ${ }^{3}$ ). Las especies ya no serían más consideradas estáticas, sino por el contrario, en continua evolución y más importante aún, será la ruptura del esencialismo como corriente dominante y de la concepción de que la variabilidad dentro de las especies es la norma. Es a partir de Darwin que surge lo que posteriormente será denominado pensamiento poblacional o population thinking. Fue impactante la fuerza que esta teoría tuvo (a pesar de las discusiones existentes acerca de cómo se produce esa evolución), no sólo en el campo de las ciencias naturales sino en todos los campos del conocimiento. En términos del epistemólogo Thomas Kuhn (1922-1996), podemos hablar de un verdadero paradigma evolutivo. Hoy, a más de 150 años de la aparición del The origin of species by means of natural selection... (Darwin, 1859), continuamos bajo este paradigma. El principal punto de cambio a partir de Darwin en relación a la clasificación de los organismos fue el hecho de considerar como único sistema válido de clasificaciones al sistema basado en las relaciones filogenéticas.

\section{La ampliación de lo'real'y y las nuevas clasificaciones}

Continuando con las clasificaciones, tanto Lineo como Darwin mantenían la noción de los dos grandes reinos de Aristóteles: el reino animal y el reino vegetal. Esta clasificación estaba basada en similitudes morfológicas reconocidas a simple vista. El avance de la tecnología permitió la ampliación de lo que podía ser considerado y analizado para realizar clasificaciones de lo vivo. El biólogo y filósofo alemán Ernst Haeckel (1834-1919) introdujo, en 1866, un tercer reino que desafiaba la antigua forma de clasificación de lo vivo en animales y plantas. Protistas, tal como fue denominado, estaba constituido por formas 
unicelulares que no podían ser categorizadas en los reinos conocidos hasta ese momento. En 1938 y posteriormente en 1956, el biólogo estadounidense Herbert Copeland (19021968) realiza una reclasificación e introduce un cuarto reino, denominado monera (que consistía básicamente en lo que se denominará posteriormente bacterias) (Coppeland, 1938, p.383-420). El naturalista francés Edouard Chatton (1883-1947), en el mismo año, descubre que las células pueden ser divididas en dos grandes grupos en base a sus características morfológicas: aquellas que poseen núcleo y organelas internas y aquellas que no (Chatton, 1938). Y propone clasificar a los organismos que contienen el primer tipo de células como eucariotas y aquellos que no, como procariotas. Por fin, en 1959, el botánico y ecólogo vegetal norteamericano Robert Whittaker (1920-1980) propuso un quinto reino, el de los hongos (Whittaker, 1959, p.210-226). Tenemos así dos sistemas clasificatorios - la dicotomía eucariotas-procariotas y el esquema de cinco reinos: animal, vegetal, protista, monera y hongos - que coexistieron durante bastante tiempo a pesar de presentar un cierto grado de incompatibilidad. El sistema dicotómico - que, si bien nunca fue concebido de este modo, debería haber sido considerado como de una jerarquía mayor a la del reino - encontró diversos problemas, especialmente dentro de los procariotas y los eucariotas unicelulares. ${ }^{4}$ Pero a pesar de que nuevos sistemas han sido propuestos para reemplazar al sistema dicotómico, éste no ha desaparecido como sistema de clasificaciones y continúa siendo utilizado ampliamente dentro de la comunidad científica. ${ }^{5}$

A partir de los años 1960 surge la biología molecular como una disciplina que explica los procesos biológicos a nivel molecular. Los avances metodológicos y teóricos obtenidos en esta área permitieron contar con nuevos rasgos que podían ser utilizados para clasificar organismos vivos. Es decir, se ampliaron las características a partir de las cuales es posible generar clasificaciones de lo vivo. Cientos de moléculas son secuenciadas año a año, las bases de datos se llenan de secuencias y la tecnología avanza rápidamente teniendo equipamientos cada vez más potentes que permiten conseguir secuencias de genomas completos en menos tiempo. A partir del desarrollo de la tecnología en el área molecular entramos en un 'paradigma molecular' donde se sostiene que todo tipo de información biológica sobre un organismo puede ser obtenida a partir de sus genes. Así se construye la noción de que toda la historia de la vida en este planeta puede ser conocida a partir de la información preservada en los genes de los organismos presentes hoy en día. En las palabras del microbiólogo norteamericano Carl Woese (1928- ) "la historia genealógica de un organismo está escrita de una u otra forma en las secuencias de cada uno de sus genes" (Woese, 2000, p.8393) y ésta es la base de una nueva disciplina denominada evolución molecular. Otra de las novedades, en relación a las clasificaciones biológicas, en la segunda mitad del siglo XX, es el desarrollo de un método denominado 'cladismo' por el cual se asume que es posible establecer las relaciones filogenéticas entre organismos en base a una serie de principios y presupuestos, entre ellos que la naturaleza tiene una estructura jerárquica, la cual puede ser develada a partir del análisis de caracteres derivados, compartidas por un grupo. El método exige que los caracteres usados para comparaciones filogenéticos posean novedades evolutivas. Fue publicado por primera vez en alemán, en 1950, por el biólogo alemán Willi Hennig (1913-1976) y revisado y traducido para el inglés en 1966 (Hennig, 1966). Hennig propone un nuevo método de reconstrucción de filogenia basado en caracteres 
morfológicos (Hennig, 1950). El cladismo es un abordaje alternativo que considera a las relaciones filogenéticos como de importancia central en las clasificaciones biológicas. Debe asumirse el principio de parsimonia, es decir, será considerada correcta aquella filogenia que explique una determinada diversidad biológica en el menor 'número de pasos' evolutivos. Los grupos parafiléticos no son considerados naturales para fines de clasificación (ver Figura 2, árbol de la izquierda. Allí, el grupo representado por los individuos A, B, C y $\mathrm{D}$ es monofilético - todos tienen un origen común. Ya si considerásemos a los individuos A, B, E y F, el grupo es parafilético ya que A y B tienen un origen diferente que E y F). Es decir, no puede considerarse como 'grupo natural' aquel que contenga entidades pertenecientes a grupos con orígenes diferentes. Se asume que la clasificación resultante refleja detalladamente y sin ambigüedades la filogenia. La forma de representación de estas filogenias es en la forma de cladogramas. Las especies existen entre los puntos de bifurcación. Cada vez que existe una bifurcación dos nuevas especies aparecen y una antigua deja de existir.

A partir de los avances de la biología molecular, un nuevo sistema clasificatorio es propuesto, en 1990, por Carl Woese (Woese, Kandler, Wheelis, 1990, p.4576-4579). En él se incluye una nueva categoría taxonómica denominada 'dominio' (ver Figura 1 para una representación gráfica de este sistema). Veamos de qué se trata para después analizar los presupuestos en los cuales se basa. La clasificación se basa en la comparación de las secuencias nucleotídicas de moléculas consideradas universales ${ }^{6}$ siguiendo los presupuestos del cladismo. La clasificación resultante se conoce como Sistema de Clasificación Universal (Figura 1). ${ }^{7}$ Los defensores de este sistema de clasificación sostienen que el mismo es 'natural' en los taxones superiores (dominio) y que provee además de un sistema que permite una clasificación totalmente natural de los microorganismos (Woese, Kandler, Wheelis, 1990, p.4579).

A partir de la propuesta de este sistema de clasificación de lo vivo en dominios, se ha generado una polémica en relación a la importancia del mismo, principalmente con los defensores del sistema dicotómico procariotas-eucariotas - del cual Ernst Mayr (1998, p.97209723) $)^{8}$ fue su mayor exponente.

\section{Formas de clasificar lo vivo, formas de pensar lo vivo}

Los modos de pensamiento dominantes durante el siglo XX pueden ser divididos en dos grandes líneas de pensamiento (O’Hara, 1997, p.323-329), ambos antiesencialistas, con raíces históricas profundas y que han sido ampliamente aceptados durante buena parte del siglo pasado. El llamado pensamiento poblacional (population thinking) fue el principal referente dentro del área de sistemática y evolución en los comienzos del siglo. Este abordaje aparece como alternativa a las nociones denominadas esencialistas o tipologistas concebidas anteriormente. El pensamiento poblacional tuvo el mayor impacto durante los años de la síntesis o teoría sintética de la evolución. ${ }^{9}$ Esta forma de pensamiento es totalmente contraria al esencialismo, no considera la existencia de tipos o 'formas naturales'. Por el contrario, la variación se convierte en la norma. Las variaciones individuales dentro de las especies, según esta perspectiva, son el resultado de un proceso continuo de 
mutación y recombinación. El filósofo de la ciencia Elliot Sober (1980, p.370) sostiene que "más que mirar a una realidad que subraya la diversidad, el pensamiento poblacional postula una realidad sustentada por la diversidad". ${ }^{10}$

Está claro que si bien esta perspectiva comenzó a ser concebida a partir de la teoría de la evolución de Darwin, necesitó de los avances de la genética y la herencia para consolidarse definitivamente. Hoy en día, tanto la sistemática como la evolución, se encuentran totalmente permeadas por esta forma de pensamiento. En el campo de las ciencias naturales ya no se conciben las ideas esencialistas. Sin embargo, como bien señala el biólogo e historiador de la ciencia, Robert O'Hara (1997, p.324), "en la medida que las nociones médicas sobre la salud y la enfermedad han ido focalizándose más en los rasgos genéticos de los individuos, existe una tendencia en los practicantes de la medicina de patologizar variaciones normales dentro de las poblaciones humanas, y así resurge la idea de un tipo natural del Homo sapiens, idea rechazada ampliamente por la biología evolutiva".

La segunda gran línea de pensamiento es denominada pensamiento en árbol (tree thinking) y caracteriza al periodo de la sistemática filogenética. La misma no se piensa como una sustitución al pensamiento poblacional, sino más bien como una contraparte filogenética al pensamiento poblacional (O'Hara, 1997, p.324). El foco principal de esta línea es la explicación de los eventos evolutivos y de cuando ocurrieron en un árbol filogenético. Está totalmente basado en los presupuestos del cladismo, a pesar de que actualmente existen otras metodologías de reconstrucción filogenética: métodos basados en distancia, métodos de máxima similitud y, más recientemente, métodos baysianos para reconstrucción filogenética.

\section{Reflexionando acerca de las clasificaciones}

\section{La naturaleza de las clasificaciones: ¿teorías o taxonomías?}

Woese (1994, p.1) discute que la clasificación dicotómica procariotas-eucariotas nunca fue una idea correctamente testada. Cabe la pregunta, si existe alguna clasificación plausible de ser testada. ¿Cómo testamos un sistema de clasificaciones? Es interesante ver como este nuevo sistema gana rápidamente el peso de verdad y no de modelo explicativo que compite con otros modelos posibles (a pesar de la existencia de otros autores que no aceptan totalmente esta visión, este sistema es ampliamente aceptado en nuestros días). La conjunción de la teoría evolutiva con la biología molecular hace de este sistema clasificatorio (taxonomía) un modelo explicativo (teoría). En verdad, lo que parece estar atrás de este modelo es la antigua concepción del Sistema Natural siendo develado y no simplemente ordenado. O'Hara (1996, p.82) reflexiona sobre los sistemáticos del pasado como "reconstruyendo un gran objeto particular que llamaban el Sistema Natural y no como construyendo clasificaciones".

¿Será que los sistemáticos modernos están en la misma línea de pensamiento que aquellos del pasado? Woese (Woese, Kandler, Wheelis, 1990, p.4576) escribe que el anhelo de Darwin de "llegar el día en que las relaciones de genealogía de todos los organismos fuesen conocidas" fue cumplido a partir de la construcción del árbol genético universal y dice "ha llegado el momento de conectar a la taxonomía formal en línea con el Sistema Natural 
que emerge a partir de los datos moleculares". ${ }^{11}$ Dentro de esta lógica se considera que una explicación sobre cualquier fenómeno biológico debe incorporar al proceso evolutivo que "en muchos casos se convierte en la esencia de la explicación. [Y] esta perspectiva debe también considerarse en las clasificaciones biológicas" (Wheelis, Kandler, Woese, 1992, p.2930). Ya para Mayr (1998, p.9722), exponente del pensamiento poblacional, una clasificación es un sistema de almacenamiento y de rescate, cuyo objetivo es "localizar un ítem con el menor esfuerzo y la menor perdida de tiempo"..$^{12}$ Quedan así en evidencia, las diferentes perspectivas de cada una de estas líneas de pensamiento.

Para Woese, la idea de que los genes guardan toda la información necesaria para reconstruir la filogenia de organismos es esencial. Para Mayr, las características morfológicas son esenciales para discernir entre lo similar y lo diferente. Woese, al defender la clasificación en tres dominios basándose en secuencias de moléculas, defiende una biología vista desde una perspectiva muy diferente a la de Mayr. Asume un cierto reduccionismo, donde el rasgo principal de donde extraer información de un organismo es a partir de la secuencia de alguno de sus genes. No importa, bajo esta perspectiva, aquellas características morfológicas, anatómicas o menos aún ecológicas, sino aquello 'impreso' en los genes.

Es claro que estos autores están hablando de diferentes tipos de sistemas. Woese considera la existencia real de un 'sistema natural'. Entiende que si comprendemos las relaciones evolutivas entre diferentes organismos, entonces la forma 'correcta' de clasificarlos será de acuerdo a esas relaciones.

Algunos problemas con este sistema natural, explicado a partir de relaciones filogenéticas, son la existencia de fenómenos como la transferencia horizontal de genes ${ }^{13} \mathrm{o}$ la posible existencia de más de un ancestro común, ambos fenómenos considerados altamente frecuentes en organismos procariotas (o en bacteria y archaea, según la clasificación de Woese).

\section{¿Un reduccionismo ribosomático?}

Volviendo a la Figura 1, voy a analizar básicamente tres puntos que están presupuestos en la topología de este árbol. Por un lado, la noción de ancestro común representada por un árbol con un único tronco. Por otro, la continua divergencia de las ramas y por último, los 'extremos' de las ramas que están representadas por las propias unidades de ese sistema de clasificación: las especies.

Antes de ver cuáles son las características de este árbol, es interesante remarcar que en la generación de clasificaciones se asume que la evolución tiene la forma de un árbol. El árbol mostrado en la figura no es, claro está, el único posible. Existen otros posibles; pero en cuanto a su topología, serán bastante similares a lo que vemos aquí siendo aceptado como el mejor modelo para representar al proceso evolutivo y las relaciones entre los organismos - i.e. un único tronco representando al ancestro común, ramas que divergen continuamente, la subordinación a una única categoría superior. En particular, este árbol fue construido en base a las relaciones entre secuencias del RNA ribosomal. Para construir este árbol, tenemos que asumir, antes que cualquier otra cosa, que las relaciones que encontremos entre moléculas de RNA representan fehacientemente las relaciones que existen entre los organismos de donde fueron extraídas. El inventario de los genes seria una forma fiel de 
comprender al inventario de organismos. En verdad, como ya mencioné anteriormente, bajo el paradigma de la biología molecular todo hace sentido dentro de su propia lógica molecular. Es cada vez más corriente la convicción de que todo tipo de información biológica puede ser extraída de los genes.

\section{Ancestro común y los problemas de los que sobran y los recién llegados}

Continuando con la figura del árbol filogenético, desde su base, nos encontramos con la primera de las hipótesis de este modelo: hipótesis de ancestro común. Cuando los biólogos consideran las posibles razones por las cuales una especie exhibe un determinado rasgo o característica, normalmente piensan a ese rasgo como habiendo evolucionado contra un background de rasgos ya 'localizados'. Así, infieren lo que debió ser la condición ancestral, asumiendo que existe un nexo filogenético que une esas especies entre sí. Así, caracteres en especies 'hermanas' son leídos 'hacia atrás', hacia el pasado, usando el principio de parsimonia, teniendo, de esa manera, una noción del carácter en cuestión en el pasado. Bajo esta perspectiva, y bajo la propia figura de un árbol con una raíz única (en verdad un tronco único) está el concepto de que todos los organismos descienden de un único ancestro común. Hoy en día, existen algunas líneas dentro de la biología que consideran a ese 'ancestro' como una población de entidades (Woese, 2002) ${ }^{14}$, una vida pre-celular que estaría constituida por tipos simples y poco organizados donde existiría un gran número de poblaciones con altos grados de transferencia horizontal de genes. De esta manera se define un umbral darwiniano que representaría el pasaje, de una etapa donde las formas serian altamente efímeras y donde la evolución de las mismas se daría principalmente por transferencia horizontal, a una etapa en donde estas formas serían cada vez más permanentes, y más refractarias a la transferencia horizontal. Lo que evolutivamente estaría 'antes' de este umbral no serían individuos o células, en la forma en que son concebidos hoy. El árbol de la vida representaría los eventos ocurridos a posteriori de ese umbral. Esta hipótesis no niega en verdad la posibilidad de que haya habido más de un 'inicio' pero con la condición de que todos ellos, con excepción de uno, se hayan extinguido.

La noción de ancestro común aparece desde Darwin, y se la considera fuertemente apoyada por la quasi universalidad del código genético ${ }^{15}$ y por algunas características universales de las moléculas biológicas. ${ }^{16}$ Francis Crick (1968, p.367) - ganador del premio Nobel de 1967 por la descripción de la estructura del DNA junto a James Watson - sostiene que esta universalidad de todos los organismos significa que están genealógicamente relacionados y señala al código genético como un 'accidente congelado', siendo una de otras varias alternativas posibles. Para esto hay que considerar al código genético como carente de un valor adaptativo o sea, no tendría un valor adaptativo el hecho de que un determinado codón codifique para un determinado aminoácido y no para otro. ${ }^{17}$ Por lo tanto, el hecho de que prácticamente todos los organismos vivos presenten el mismo código genético, y que este no contenga ningún ventaja adaptativa, habla a favor de un origen común de todos los organismos. Otra hipótesis a favor del ancestro común fue la del bioquímico ruso Alexander Oparin (1894-1980) quien sugirió que, una vez que la vida surge a partir de materia no animada, altera el medio ambiente de forma tal que la 
probabilidad de aparición de nueva vida sería mínima (Oparin, 1953). En cuanto a la hipótesis de ancestro común, vale la pena leer con atención el artículo de Sober y Steel (2002, p.395-408) donde son detalladas éstas y otras alternativas para testar esta hipótesis. La conclusión final del trabajo es que a pesar de esta hipótesis ser central en la teoría evolutiva moderna, no existe una metodología válida que permita testarla.

Otro de los presupuestos del árbol es la continua divergencia, cada nodo se abre en una nueva bifurcación. Visto desde la raíz o ancestro común hacia las ramas lejanas, el proceso de diversificación es un proceso de constante divergencia, es decir no es posible asumir aquí la posibilidad de 'saltos o transferencias horizontales' o procesos de hibridación de especies. La jerarquía en el árbol se representa como continuos procesos de bifurcación. Pero, ¿podría verse de una forma diferente? (Figura 2).

El evolucionista Maynard Smith (1920-2004) levanta la siguiente cuestión (Maynard Smith, 1989): ¿existe alguna manera que permita discernir si la figura más apropiada para describir el proceso que dio origen a un conjunto de objetos es un árbol, un arbusto o un nido? Esto es bien diferente a la pregunta levantada por los taxonomistas que, en general asumiendo a un árbol como la figura apropiada, se preocupan con encontrar el mejor de los árboles posibles. Maynard Smith sostiene que otro tipo de representaciones podrían ser útiles al comparar el universo procariota, pero no así el universo eucariota. La cuestión es cómo clasificar a los procariotas y cómo representar una evolución que se haya dado de una manera diferente. En este sentido, la taxonomía bacteriana aún no ha llegado a un consenso en relación a su clasificación y a la propia definición de especies. Se ha sugerido el concepto de ecotipo para definir a una población de células que comparten un nicho ecológico. Para estos casos, es probable que una topología diferente fuese más apropiada que un árbol para representar las relaciones entre diferentes especies. Por otra parte, la existencia de elementos genéticos como elementos de transposición ${ }^{18}$, virus y formas híbridas, no son ni siquiera considerados en la clasificación del 'árbol de la vida'. En verdad, si son los genes lo que estamos utilizando para realizar filogenias de organismos, entonces deberíamos poder asumir qué fenómenos, como transferencia horizontal, tienen sentido y deberíamos ser capaces de incorporarlos y representarlos en los sistemas clasificatorios.
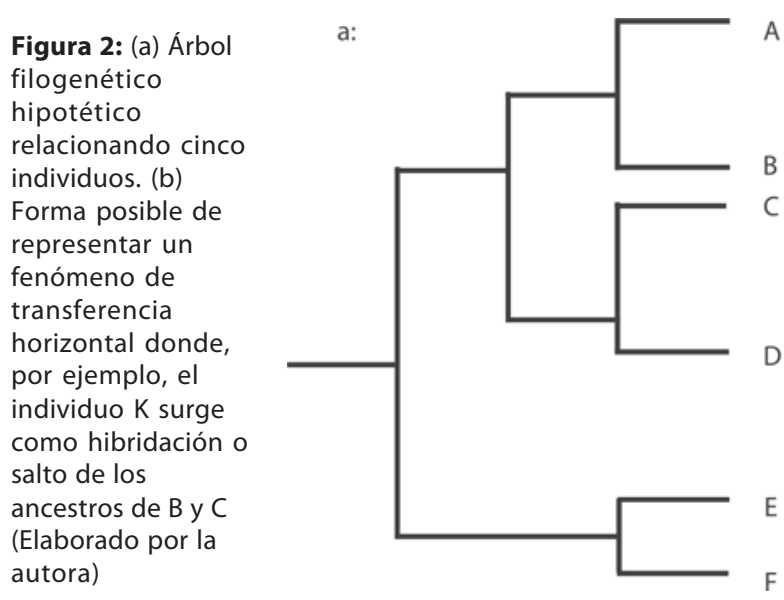

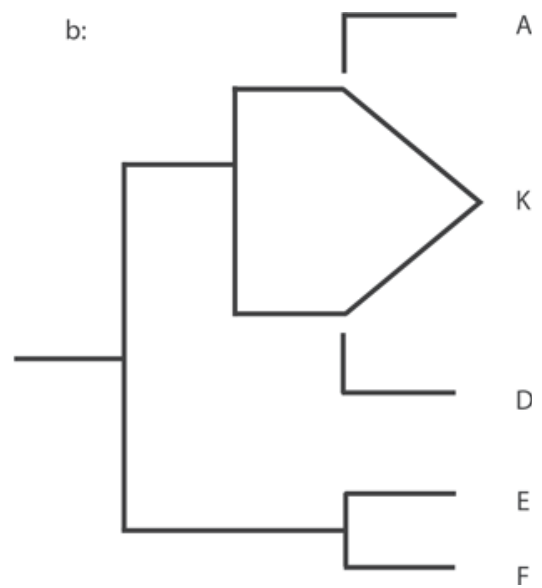




\section{Sobre especies, ¿grupos, individuos o simplemente categorías?}

Siguiendo con el análisis del árbol filogenético, llegamos a la 'copa' del árbol y allí nos encontramos con la categoría básica en nuestros sistemas clasificatorios: las especies. ¿Cómo se define una especie? ¿Cuál es su estatus ontológico? Este no es un problema nuevo ni para la biología ni para la filosofía. Ambas disciplinas continúan debatiéndose a este respecto, tanto que actualmente existen más de veinte definiciones de especies solamente considerando organismos eucariotas. Veamos aquí cuáles son las principales controversias que existen. En cuanto a la definición biológica de especie, existen varias definiciones, todas ellas con sentido bajo diferentes perspectivas. Por un lado, así como se considera a las especies como unidades básicas de los sistemas de clasificación, son también consideradas como las unidades básicas de la evolución ${ }^{19}$, como un grupo de individuos que evolucionan de forma unificada. También existe una definición ecológica de especie, así como también, una cromosómica, una evolutiva, una filogenética y algunas otras. Existen además, en cuanto a la propia definición de especies, aquellos para quienes es preciso hallar la definición única y 'correcta' del término, llamados monistas o puristas y aquellos pluralistas, para quienes no existe un único concepto y deben aceptarse todas las diversas acepciones del termino. ${ }^{20}$

Por otra parte, algunos filósofos consideran que las especies deben ser tratadas como tipos naturales o esenciales (natural kinds), en cuanto otros consideran a las especies como individuos (Ghiselin, 1974 y; Hull, 1978 según cita en Ereshevsky, 2004). Veamos brevemente cuáles son las discusiones que existen en torno al concepto de especie. En biología, a partir de la teoría evolutiva de Darwin, el esencialismo, aplicado al concepto de especie, dejó de tener sentido. Encontrar rasgos o caracteres que ocurran en todos y únicamente en los miembros de una determinada especie (concepto esencialista de especie de los tiempos de Aristóteles que fue predominante hasta el siglo XIX) parece una tarea imposible. La visión tradicional que los organismos pueden ser divididos en clases discretas de forma no ambigua, basándonos en características morfológicas, se torna insustentable a partir de la teoría de evolución que ha echado por tierra la idea de que las especies son entidades fijas. El filósofo John Dupré (1952- ) llama de 'realismo taxonómico' a la visión de que habría una teoría taxonómica única y correcta (Dupré, 1981, p.73). En cada nivel taxonómico habría un corte claro y un criterio universal, capaz de generar una división exhaustiva de los individuos en taxa diferente. Cada individuo tendría, entonces, todas las propiedades de todos los taxa a los cuales pertenece. Por otro lado, parece cada vez más razonable la noción de que algún tipo de característica micro estructural (Kitts, 1979, según cita en Dupré, 1981, p.83) sea descubierta (en los genes por ejemplo) y que esto nos permita clasificar de manera no ambigua diferentes individuos en diferentes especies.

El argumento de Hull (1965, p.1-18), contra el esencialismo en cuanto a la definición de especie, radica en el hecho de que las especies no tienen límites concretos y definidos. Esta frontera, poco delimitada, sería incompatible con la existencia de esencias específicas para las especies. Dupré (1981, p.84) sigue la misma línea de razonamiento. De alguna forma, las explicaciones esencialistas fueron reemplazadas en su momento por el pensamiento poblacional, vinculado a las concepciones evolutivas. La teoría evolutiva provee los métodos para explicar las diferencias (variabilidad) entre los miembros de una especie, por lo tanto, el esencialismo no es una explicación posible. 
Una propuesta alternativa en cuanto al estatus ontológico de la especie es la que las considera individuos y no clases (éstas serían un grupo de entidades sobre la cuales puede funcionar una ley científica) (Ghiselin, 1974 y; Hull, 1978, según cita en Ereshevsky, 2004). Ellos proponen que las especies no son tipos o clases universales, sino individuos. El nombre de la especie sería un nombre propio, el nombre de un individuo único y singular que tiene un comienzo, una historia y una extinción y que también tiene una distribución en el espacio.

Según esta perspectiva, las especies no pueden ser consideradas un natural kind, ya que lo único de esencial en una especie es la propia variabilidad. Las especies, vistas de esta forma, serían la única categoría taxonómica 'real'. Pertenecer a una especie sería pertenecer a un determinado linaje, considerando a la especie como un término teórico dentro de la teoría evolutiva, y no el hecho de ser similar a otros miembros de la especie. Algunos otros autores, sin embargo, piensan que postular a las especies como 'reales' e 'individuales' es una forma de esencialismo. Llevando esta forma de pensamiento a su extremo, puede decirse que las categorías taxonómicas son individuos y, por lo tanto, no existen características esenciales en ninguna de ellas o una idea más provocadora. Citando a Dupré (2002, p.30).

En cuanto a la relación entre especie y taxa superiores, creo en verdad que el nivel de especie es el único nivel taxonómico al cual no pueden atribuírsele propiedades esenciales. Esto no pretende ser una paradoja. Simplemente, por el hecho de los taxa superiores no tener existencia real son definidos en el vocabulario científico por nombres esenciales. La razón por la cual lo mismo no puede ser dicho acerca de las especies es que las mismas, a pesar de carecer de una esencia real, tienen un tipo de existencia real y objetiva. ${ }^{21}$

En cuanto a los 'defensores' de la concepción de especie como un natural kind, la teoría de Richard Boyd (1999, p.1) dice que los mismos son conjuntos de tipos agrupados por propiedades homeostáticas. Así, los miembros de un kind comparten un número de propiedades que ocurren simultáneamente y que pueden ser predichas y explicadas. La simultaneidad en la ocurrencia de esas propiedades se debe a mecanismos homeostáticos. En esta línea argumentativa, el concepto de natural kind es diferente al de la visión tradicional. Dos consecuencias inmediatas pueden ser mencionadas: ser parte de un kind - especie, en este caso - no requiere la ocurrencia de una propiedad universal en todos los miembros y, por otra parte, este argumento permite que las especies varíen en el tiempo, a pesar de la necesidad de ser suficientemente estables como para que puedan ser establecidas predicciones sobre alguna de sus propiedades.

El filósofo Barry Smith (1952-) manifiesta, en relación a la ontología filosófica, que:

[la misma]...provee de una clasificación definitiva y exhaustiva de las entidades en todas las esferas del ser. La clasificación debe ser definitiva en el sentido de poder servir como respuesta a preguntas como: ¿Qué clases de entidades se necesitan para alcanzar una descripción completa y una explicación de todo lo que ocurre en el universo? o ¿Qué clases de entidades se necesitan para dar cuenta de lo que hace verdadero a todas las verdades?22 (Smith, 2003, p.155).

En este trabajo de alguna manera realicé lo opuesto. Partí de las clasificaciones consideradas exhaustivas, en términos de su poder explicativo, e intenté buscar las explicaciones utilizadas para generarlas y para concebir la realidad de la manera que se la concibe. 


\section{NOTAS}

1 "natural things are exactly those which do move continuously, in virtue of a principle inherent in themselves, towards a determined goal; and the final development which results from any one such principle is not identical for any two species, nor yet is it any random result; but in each there is always a tendency towards and identical result if nothing interferes with the process". En ésta y en otras citas, la traducción es libre.

2 'Taxa' es el conjunto de unidades taxonómicas, o sea, de todas las categorías utilizadas para clasificar a los organismos. El sistema de clasificación actual considera ocho taxa diferentes para clasificar a los organismos vivos: especie, género, familia, orden, clase, phylum, reino y dominio.

${ }^{3}$ Algunos ejemplos son el matemático y naturalista francés Comte de Bufón (1707-1788) quien consideraba que los organismos vivos cambiaban con el tiempo y que esto podía deberse a factores externos o ambientales o incluso al azar; Erasmus Darwin (1731-1802), abuelo de Charles Darwin, pensaba que de hecho los organismos vivos, incluidos los humanos, evolucionaban, pero no tenía muy claro el mecanismo por el cual esto ocurría y Jean-Baptiste Lamarck que creía que los microorganismos se formaban espontáneamente y que luego transmutaban y evolucionaban lenta y progresivamente hacia formas más complejas.

${ }^{4}$ El gran problema con el cual se han deparado las clasificaciones biológicas es en lo que respecta al mundo microscópico. La tarea nunca fue fácil y hasta el día de hoy es la base de las diferentes visiones sobre las clasificaciones de lo vivo.

${ }^{5}$ Una defensa de este sistema y de los presupuestos detrás del mismo se encuentran en Ernst Mayr, 1998.

${ }^{6}$ Existen varias moléculas consideradas universales, pero las utilizadas originalmente por Woese son las subunidades 16 y 18s del RNA ribosomal. Los ribosomas son esenciales en el proceso de traducción de proteínas, son moléculas compuestas por una parte proteica y una molécula de RNA. Forman parte de todos los procesos de traducción conocidos y de allí que se las considere universales. Además son bastante constantes en estructura y función, lo que las constituye en ideales para hacer comparaciones entre organismos filogenéticamente distantes.

${ }^{7}$ Cabe señalar que algunos biólogos han argumentado que las clasificaciones de los organismos vivos deben realizarse sin hacer referencia a la teoría evolutiva. Sostienen que las clasificaciones deben basarse en similitudes fenotípicas. Estos "taxonomistas fenéticos" (Gasper, 1991, p.545-552) ofrecen dos argumentaciones para su propuesta: por un lado, la idea de que la objetividad en ciencia requiere independencia de la teoría y por otro, que si la teoría evolutiva es usada como la base para las clasificaciones, entonces la clasificación resultante no puede ser utilizada para aumentar nuestro conocimiento del proceso evolutivo. En el extremo opuesto se encuentran quienes apoyan un sistema clasificatório sin jerarquías o rangos en el cual los nombres son dados con definiciones filogenéticos (Ereshevsky, 2001, según cita en Moore, 2002, p.1650).

${ }^{8}$ Ernst Mayr fue uno de los biólogos evolucionistas más importantes del siglo XX. Nacido en 1904 en Bavaria, Alemania, vivió hasta los 101 años, lo que le permitió ser testigo y formar parte de los varios debates en relación a la teoría de la evolución, al proceso de especiación y a la propia definición de especie. En 1942 publicó una de sus obras más importantes, Sistemática y origen de las especies desde el punto de vista de un zoólogo donde propone el concepto biológico de especie, es decir como un conjunto de individuos capaces de reproducirse solamente entre sí. Este concepto fue de fundamental importancia y constituye, hasta hoy, uno de los conceptos fundamentales de la biología.

${ }^{9}$ La teoría sintética de la evolución surge en 1942 a partir del libro de Julian Huxley, Evolution: the modern sinthesis, pero es el producto del trabajo de varios autores en el área de evolución en las primeras décadas del siglo XX. La 'síntesis' es una teoría que básicamente une los conceptos de la teoría de la evolución de Darwin con los avances en el área de la genética. Ver Mayr, 2004, como un ensayo personal escrito por el único testigo que vivió durante toda esa época.

10 "Rather than looking for a reality that underlines diversity, the populationist can postulate a reality sustained by diversity".

11 "the time has come to bring formal taxonomy into line with the Natural System emerging from molecular data".

12 "to locate an item with a minimum of effort and loss of time".

${ }^{13}$ La transferencia horizontal o lateral de genes se llama al proceso por el cual un organismo incorpora material genético de otro sin ser su descendiente ni estar emparentado con él. En bacterias existen tres tipos: conjugación, transformación e transducción. 
${ }^{14}$ Este artículo de Woese es un excelente punto de partida hacia una nueva teoría de la organización celular y una nueva hipótesis sobre los orígenes de la vida.

${ }^{15}$ Código genético universal se refiere al hecho de que todas las proteínas, de todos los organismos conocidos, son codificadas a partir de los mismos codones del DNA.

${ }^{16}$ Todos los aminoácidos, de todas las proteínas, de todos los seres vivos están formados por moléculas levógiras. Es decir, que desvían hacia la izquierda la luz polarizada. En verdad esto en sí no tiene ninguna importancia, pero nada impide que estos aminoácidos sean dextrógiros (que desvíen hacia la derecha). De hecho, cuando son sintetizados en el laboratorio una composición 50-50\% es producida. Pero en la naturaleza, $100 \%$ de ellos son levógiros. Esto se ha considerado un punto a favor de la hipótesis de origen común.

${ }^{17}$ Los tripletes o codones son conjuntos de tres nucleótidos consecutivos en la secuencia de DNA o RNA que son 'leídos' o codificados como un determinado aminoácido en la secuencia proteica. Así por ejemplo, UUU codifica para fenilalanina y no para metionina (otro aminoácido codificado por un triplete diferente).

${ }^{18}$ Los elementos de transposición son elementos genéticos presentes en los genomas de todos los organismos. Codifican para una/s enzima/s encargada/s de su propia multiplicación y por esto han sido la base de la teoría del gen egoísta. Estos elementos sufren altas tasas de transferencia horizontal entre organismos filogenéticamente no emparentados.

${ }^{19}$ Existen controversias al respecto de cuales son las unidades de la selección natural. ¿Cuáles son aquellas unidades importantes a las que se aplica la selección natural? Por un lado, tenemos a los organismos, por otro, a las poblaciones o a las especies como unidades evolutivas y también quienes consideran que en verdad los genes son las verdaderas unidades evolutivas.

${ }^{20}$ Ver Ereshevsky, 2004, para un resumen de los diferentes aspectos relacionados con la definición de especie.

21 "on the relation between species and higher taxa, I actually believe that the species is the only taxonomic level to which essential properties cannot be atributed. This is not meant as a paradox. It is merely that higher taxa, having no real existence, are defined in scientific vocabulary by nominal essences. The reason that the same cannot be said of the species is that species while lacking a real essence, do have a kind of real, objective existence".

22 "it provides a definitive and exhaustive classification of entities in all spheres of being. The classification should be definitive in the sense that it can serve as an answer to such questions as: What classes of entities are needed for a complete description and explanation of all the goings-on in the universe? Or: What classes of entities are needed to give an account of what make true all truths?"

\section{REFERENCIAS}

BOCK, Kenneth.

Theories of progress, development, evolution. In: Ottomore, T. and Nisbet, R. (Ed.). A history of sociological analysis. New York: Basic Books. p.39-79. 1978.

BOYD, Richard.

Homeostasis, species, and higher taxa. In:

Wilson, Robert A. (Ed.). Species: new

interdisciplinary essays. Cambridge, MA: MIT Press. 1999.

CHATTON, Edouard.

Titre et travaux scientifique. Sottano: Sette. 1938.

COPPELAND, Herbert F.

The kingdoms of organisms. The Quarterly Review of Biology, Chicago, v.13, p.383-420. 1938.

CRICK, Francis.

The origin of the genetic code. Journal of
Molecular Biology, Cambridge, MA, v.38, n.3, p.367-379. 1968.

DARWIN, Charles.

The origin of species by means of natural selection or the preservation of favoured races in the struggle for life. London: John Murray. $1^{\text {st }}$ ed., 1859.

DUPRÉ, John.

Humans and other animals. Oxford: Oxford University Press. 2002.

DUPRÉ, John.

Natural kinds and biological taxa. Philosophical Review, Ithaca, v.90, n.1, p.66-90. 1981.

ELLEN, Roy.

Classification. In: Barnard, Alan; Spencer, Jonathan (Eds.). The Routledge encyclopedia of social and cultural anthropology. London: Routledge, second edition, p.129-133. 2010. 
ERESHEVSKY, Marc.

Species. In: Zalta, Edward N. (Ed.). The Stanford encyclopedia of philosophy. Disponible en: http:// plato.stanford.edu/archives/sum2004/entries/ species/. Consultada em: 15 nov. 2010. 2004.

\section{GASPER, Philip.}

The philosophy of biology: introductory essay. In: Boyd, Richard; Gasper, Philip; Trout, J.D.

(Ed.). The philosophy of science. Cambridge, MA: MIT Press. 1991.

HAECKEL, Ernst.

Generelle Morphologie der Organismen. Berlin: Reimer. 1866.

HENNIG, Willi.

Phylogenetic systematics. Urbana: University of Illinois Press. 1966.

HENNIG, Willi.

Grundzüge einer Theorie der phylogenetischen Systematik. Berlin: Deutscher Zentralverlag. 1950.

HULL, David.

The effect of essentialism on taxonomy: two thousand years of stasis. British Journal for the Philosophy of Science, Leeds, v.15, p.314-326; v.16, p.1-18. 1965.

MAYNARD SMITH, John.

Trees, bundles or nets? Trends in ecology \& evolution, Oxford, v.4, p.302-304. 1989.

MAYR, Ernst.

80 years of watching the evolutionary scenery. Science, Washington, v.305, n.5680, p.46-47. 2004.

MAYR, Ernst.

Two empires or three? Proceedings of the National Academy of Sciences, Washington, v.95, n.17, p.9720-9723. 1998.

MAYR, Ernst.

The growth of biological thought. Cambridge, MA: Harvard University Press. 1982.

MCLAUGHLIN, Paul.

Toward an ecology of social action: merging the ecological and constructivist traditions.

Human Ecology Reviews, Salt Lake City, v.8, n.2, p.12-28. 2001.

MOORE, Gerry.

Down with the kingdom (phylum, class and order too). Science, Washington, 297, p.1650-1651. 2002.

O'HARA, Robert.

Population thinking and tree thinking in systematics. Zoologica Scripta, Oslo, v.26, n.4, p.323-329. 1997.
O'HARA, Robert.

Trees of history in systematics and philology: sistematic biology as an historical science. Memorie della Societá Italiana di Scienze Naturali e del Museo Civico di Storia Naturale di Milano, Milano, v.26, n.1, p.81-88. 1996.

OPARIN, Alexander.

The origin of life. New York: Dover. 1953.

SMITH, Barry.

Real and virtual worlds: ontology. In: Luciano, Floridi (Ed.). Blackwell guide to the philosophy of computing and information. Oxford: Blackwell. p.155-166. 2003.

SOBER, Elliot.

Evolution, population thinking and essentialism. Philosophy of Science, Leeds, v.47, p.350-83. 1980.

SOBER, Elliot; STEEL, Michael.

Testing the hypothesis of common ancestry. Journal of Theoretical Biology, Michigan, v.218, p.395-408. 2002.

WHEELIS, Mark L; KANDLER, Otto; WOESE, Carl Robert.

On the nature of global classification.

Proceedings of the National Academy of Sciences, Washington, v.89, n.7, p.2930-2934. 1992.

WHITTAKER, Robert.

On the broad classification of organisms. The Quarterly Review of Biology, Chicago, v.34, p.210226. 1959.

WOESE, Carl Robert.

On the evolution of cells. Proceedings of the National Academy of Sciences, Washington, v.99, n.13, p.8742-8747. 2002.

WOESE, Carl Robert.

Interpreting the universal phylogenetic tree. Proceedings of the National Academy of Sciences, Washington, v.97, n.15, p.8392-8396. 2000.

WOESE, Carl Robert.

There must be a prokaryote somewhere: microbiology's search for itself. Microbiology and Molecular Biology Reviews, Washington, v.58, n.1, p.1-19. 1994.

WOESE, Carl Robert; KANDLER, Otto; WHEELIS, Mark.

Towards a natural system of organisms: proposal for the domains archaea, bacteria and eucarya. Proceedings of the National Academy of Sciences, Washington, v.87, p.4576-4579. 1990. 